\title{
The effects of external shocks on the Korean economy: CGE model-based analysis
}

\author{
Hyeok Lee(i) and Yong Kyun Kim*
}

*Correspondence:
ykkim0909@gmail.com
Yonsei University, 50,
Yonsei-ro, Seodaemun-gu,
Seoul, Republic of Korea

*Correspondence: ykkim0909@gmail.com Seoul, Republic of Korea

\begin{abstract}
The trend of low commodity prices looks to continue. Such a trend will affect small open economies that are heavily commodity import dependent, such as the economy of South Korea. Hence, it is of interest to see how the economy would have performed differently with changes in the imported commodity price. In order to systematically investigate this effect, this paper utilizes the Computable General Equilibrium model. In applying the model, maximum entropy estimation approach is used to estimate behavioral parameters for the model. The results of scenario analyses seem to indicate that technology intensity of the industries dictates how differently the given industry will behave with regard to the change in crude oil prices.
\end{abstract}

Keywords: CGE, External shock, Oil price, Korean economy

\section{Background}

\subsection{Global economy and oil price}

This paper aims to analyze the effects an external shock has on the Korean economy using a Computable General Equilibrium (henceforth CGE) model. The 'external shock' to be examined in this paper is changes in crude oil prices. As the Korean economy is a heavily commodity import-dependent small open economy, the recent fluctuation in crude oil prices seems an external shock that deserves due attention.

The global economy has been making a slow but gradual recovery from the financial crisis of 2008. Still, the global economy faces occasional hurdles such as the UK's vote to leave the European Union and ongoing adjustments such as China's realignment and the slow pace of recovery in the United States. However, although the effects of UK leaving the EU will certainly have long-term effects, the immediate market disruption seems to be contained. Furthermore, the global economy seems to be adapting to the ongoing adjustments and long-term trends in its path of recovery. Although the trend is toward recovery, each economy seems to be facing quite varying outlooks. The slowing of the Chinese economic machine still is a great downside risk with the continuing low commodity prices, including crude oil prices, hampering the emerging markets and commodity export economies from making a strong rebound (International Monetary Fund 2016). 
Figure 1 depicts the historic trend of the Dubai crude oil price. ${ }^{1}$ We can see that the prices fluctuate greatly since the 2008 financial crisis. Furthermore, the crude oil prices have sharply dropped to historic lows since the latter half of 2014. As Korea is heavily dependent on commodity imports, especially crude oil (also, Korea imports mainly Dubai crude oil), hikes and falls of crude oil prices always impact the Korean economy greatly and thus are of great interest. As the trend of low oil prices seems very likely to continue in the near future as can be seen in Table 1, it is of interest to see how the economy may react to such a trend.

Therefore, this paper aims to utilize the CGE model to systematically analyze the effects the change in crude oil prices have on the Korean economy. The paper is organized as follows: Following Introduction in Sect. 1, Sect. 2 explains the methodology of constructing the social accounting matrix (SAM), the system of the CGE model and

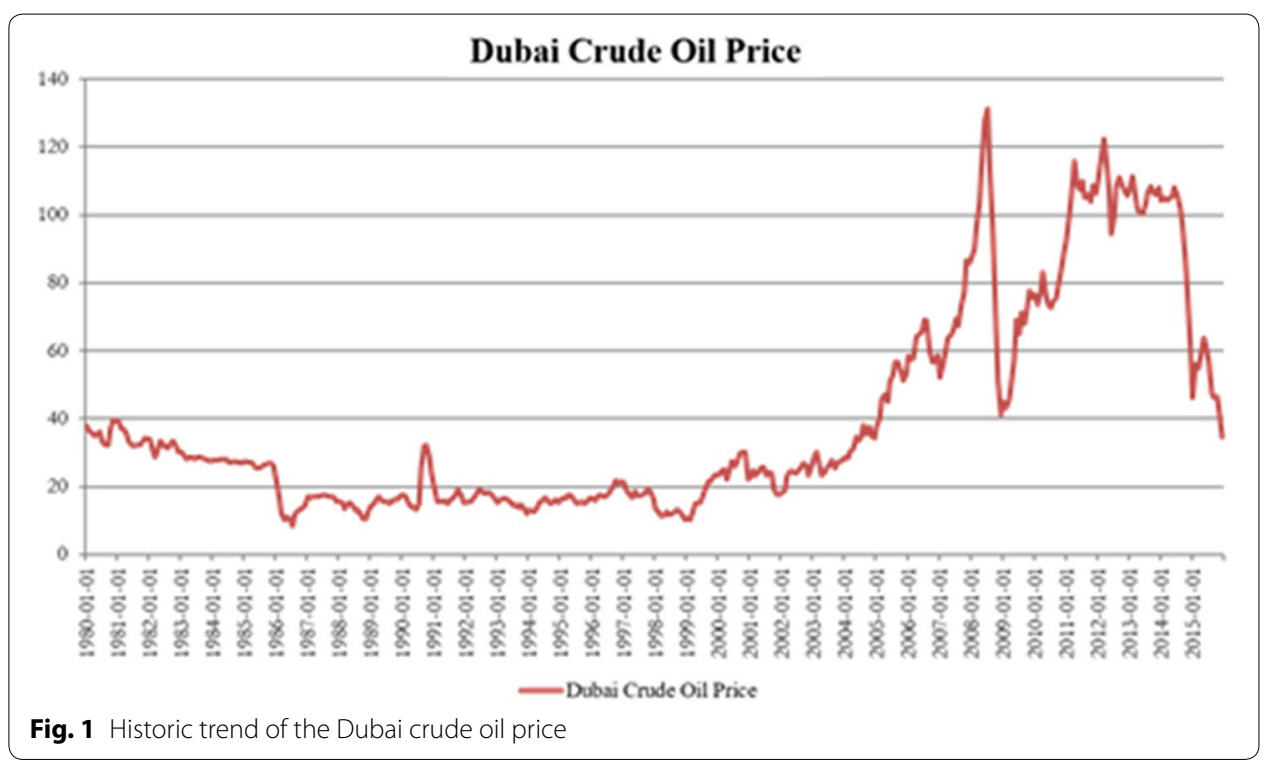

Table 1 World economy, commodity prices and consumer prices (\%, y-on-y). Source: IMF WEO October 2016

\begin{tabular}{lcccccc}
\hline & $\mathbf{2 0 1 2}$ & $\mathbf{2 0 1 3}$ & $\mathbf{2 0 1 4}$ & $\mathbf{2 0 1 5}$ & $\mathbf{2 0 1 6}$ & $\mathbf{2 0 1 7}$ \\
\hline World economy & & & & & & \\
World & 3.5 & 3.3 & 3.4 & 3.2 & 3.1 & 3.4 \\
Advanced & 1.2 & 1.2 & 1.9 & 2.1 & 1.6 & 1.8 \\
Emerging & 5.3 & 5.0 & 4.6 & 4.0 & 4.2 & 4.6 \\
China & 7.9 & 7.8 & 7.3 & 6.9 & 6.6 & 6.2 \\
Commodity prices & & & & & & \\
Oil & 1.0 & -0.9 & -7.5 & -47.2 & -15.4 & 17.9 \\
Nonfuel & -10.0 & -1.4 & -4.0 & -17.5 & -2.7 & 0.9 \\
Consumer prices & & & & & & \\
Advanced & 2.0 & 1.4 & 1.4 & 0.3 & 0.8 & 1.7 \\
Emerging & 5.8 & 5.5 & 4.7 & 4.7 & 4.5 & 4.4 \\
\hline
\end{tabular}

\footnotetext{
${ }^{1}$ Source: https://www.quandl.com/about.
} 
the parameter estimation issues. Also, Sect. 2 describes how the paper investigates the effects of the crude oil price changes have on the Korean economy via simulation using the CGE model under various scenarios. The conclusion is presented in Sect. 3.

\section{Methods}

\subsection{Social accounting matrix (SAM)}

In order to construct a fully systematic CGE model, we first need to construct a SAM. This paper utilizes the input-output table (I-O table) (Leontief 1936) at basic prices for 2013 issued by the Bank of Korea (BOK). The realized I-O table for Korea is issued by BOK every 5 years, and extended tables are issued for the years in between. The I-O table for Korea consists of 384 basic sectors. On using the I-O table, the sectors are aggregated to adequately meet the purpose of this paper.

To construct a SAM to be used in the CGE model, we need to work with an I-O table reported at producers' prices. However, BOK has switched to reporting the $\mathrm{I}-\mathrm{O}$ table only at basic prices following the table for 2010 . Hence, it is necessary to convert the I-O table valued at the basic prices to that valued at producers' prices. The accounts that need to be addressed are: Taxes less subsidies on products, Scraps, and Tariffs. In the case of the table valued at producers' price, the Taxes less subsidies on products are included in the Intermediate demand and the Final demand. However, in the case of the table valued at basic prices, Taxes less subsidies on products is reported as a separate account. Also, Scraps were included in the Intermediate demand and Final demand in the tables valued at producers' prices. However, Scraps account is now reported separately as negative values in the input side and as positive values in the demand side. In the case of Tariffs, it used to be reported as Production tax on the demand side. However, Tariffs now is reported as Taxes less subsidies on products on the Import table.

In order to make the necessary adjustments to the accounts aforementioned, we need to compare the basic prices-based and producers' prices-based I-O tables for a year in which both were issued. As BOK started to report the table in basic prices in the realized I-O table for 2010 alongside the usual producers' prices-based table, both the basic prices-based and producers' price-based table exist for 2010. In the case of the Taxes less subsidies on products, we take the sum of the Intermediate demand and Final demand balance from the Domestic table and the Import table and use the resulting ratio to appropriately distribute the Taxes less subsidies on products to each sector. For the Tariffs, we determine the Tariffs by using the rate from the Import table, and the sum of the Intermediate demand and Final demand.

As for the Scraps, BOK issued the Scrap table and the Scrap demand table in 2005. However, no such report was issued after 2005; hence, we use the 2005 tables to appropriately adjust the sectors and distribute the Scraps using the ratio from the 2005 tables to the Intermediate demand and the Final demand.

Finally, the RAS method is employed to adjust the SAM, so the row sums and the column sums are in accord.

The 384 basic sectors are aggregated into 19 sectors for analysis in this paper. The recategorized 19 sectors are as listed in Table 2 .

As this paper aims to look at how the decline and rise of the crude oil price affect the Korean economy, the Oil sector (S03) and sectors that represent possible 
Table 2 Industrial sectors

\begin{tabular}{|c|c|c|c|c|c|}
\hline & Industry & $\begin{array}{l}\text { I-O table } \\
\text { specification }\end{array}$ & & Industry & I-O table specification \\
\hline S01 & Agriculture & $1-25$ & S11 & Precision Machinery & $243-248$ \\
\hline S02 & Coal & 26,27 & $\mathrm{~S} 12$ & Transportation Equip. & $249-262$ \\
\hline S03 & Oil & 28 & S13 & Other Manufacturing & $263-273$ \\
\hline S04 & Natural Gas & 29 & S14 & Electric & $274-278$ \\
\hline S05 & Mining & $30-34$ & S15 & City Gas & 279 \\
\hline S06 & Light Industry & $36-98$ & S16 & Steam, Water and Waste & $280-286$ \\
\hline S07 & Coal Products & 99,100 & S17 & Construction & 287-301 \\
\hline S08 & Petrol Products & $101-110$ & $\mathrm{~S} 18$ & Transportation Services & 304-317 \\
\hline S09 & Heavy Chem. Ind. & $111-213$ & S19 & Service and Misc. & $302-303,318-384$ \\
\hline $\mathrm{S} 10$ & Electrical and Electronics & $214-242$ & & & \\
\hline
\end{tabular}

substitutes [Coal (S02) and Natural Gas (S04)] were left unaggregated. The industries were aggregated so as to enable analysis of the fuel flow by characteristics by industry. The aggregated industry categories are: Agriculture, Coal, Oil, Natural Gas, Mining, Light Industry, Coal Products, Petrol Products, Heavy Chemical Industry, Electrical and Electronics, Precision Machinery, Transportation Equipment, Other Manufacturing, Electric, City Gas, Steam, Water and Waste, Construction, Transportation Services, Services and Miscellaneous Industries.

\subsection{Computable general equilibrium (CGE) model}

The CGE model constructs a system of equations drawing from economic theory that describes the economy and the economic behavioral patterns of the Household, Firm and the Government. Once the model is set up to enable replicating the observed economy, simulations of various scenario settings that reflect the changes to the economy may be run to analyze the effects of the changes. As the economic system is deeply interlinked and is of a complicated construct, a change to a single industrial sector will inevitably ripple through to other relevant sectors affecting the demand and supply of the whole economy. The CGE system enables the change in demand and supply of the economy to reflect the preference of the Household and technology of the Firm and factor endowments via the system of equations.

The parameters of the production technology described within the model are acquired from the observed input-output data. The functional forms of the preference and production are taken from theory.

The CGE model 'computes' a possible 'state' of the economy from the observed 'general equilibrium' that results from the system of equations at a given point in time that represent the economy. The model system is composed of equations that define the behavioral rules of production, transformation, composite goods, income and consumption and savings, market clearing conditions. The goods in the economy are taken to be categorized as import goods, domestic goods and export goods.

Taking a closer look at the production and transformation function, there are final goods and input goods in production. The final goods are product of a function of value-added and intermediate input goods. The value added is product of a function of the input factors labor and capital. The value-added function is assumed to take a 
Cobb-Douglas functional form. The final goods are transformed into export goods and domestic goods via a transformation function which takes a Constant Elasticity of Transformation (CET) form. The production function of capital goods takes the form of a Leontief production function as intermediate composite goods as inputs. Equations (1) through (4) show the functional forms of production and transformation.

$$
\mathrm{XD}_{i}=f^{i}\left(q_{1 i}, \ldots, q_{n i}, V_{i}\right)=\min \left[\frac{q_{1 i}}{a_{q i}}, \frac{q_{2 i}}{a_{2 i}}, \ldots, \frac{q_{n i}}{a_{n i}}, \frac{V_{i}}{a_{v i}}\right]
$$

$\mathrm{XD}_{i}$ : The final good output of the $i$ th good, $V_{i}$ : The value-added input of the $i$ th good, $q_{j i}$ : The intermediate input of the $j$ th good in producing the $i$ th good, $a_{j i}$ : The input coefficient of $j$ the good in producing the $i$ th good, $a_{v i}$ : The input coefficient of value added in producing the $i$ th good

$$
\left(1-r_{i}\right) V_{i}=L_{i}^{\beta_{i}} K_{i}^{1-\beta_{i}}
$$

$L_{i}$ : The labor input in the $i$ th industry, $K_{i}$ : The capital input in the $i$ th industry, $\beta_{i}$ : CobbDouglas parameter (exponent), $r_{i}$ : Indirect tax rate

$$
\mathrm{XD}_{i}=g^{i}\left(E_{i}, \mathrm{XS}_{i}\right)=A_{i}\left[\lambda_{i} E_{i}^{\eta_{i}}+\left(1-\lambda_{i}\right) \mathrm{XS}_{i}^{\eta_{i}}\right]^{\frac{1}{\eta_{i}}}
$$

$E_{i}$ : Export goods, $X S_{i}$ : Domestic goods

$$
Z=\min \left[\frac{I_{1}}{\theta_{1}}, \frac{I_{2}}{\theta_{2}}, \ldots, \frac{I_{n}}{\theta_{n}}\right]
$$

$I_{i}$ : Investment demand for the $i$ th good, $\theta_{i}$ : The input coefficient of the $i$ th good in the capital goods production.

For consumption and the intermediate demand, the model used in this paper assumes composite goods that are composed of domestic goods and imported goods. This follows the Armington assumption (Armington 1969) and is expressed as a Constant Elasticity of Substitution (CES) function as in Eq. (5).

$$
X_{i}=h^{i}\left(M_{i}, \mathrm{XS}_{i}\right)=B_{i}\left[D_{i} M_{i}^{-\rho_{i}}+\left(1-D_{i}\right) \mathrm{XS}_{i}^{-\rho_{i}}\right]^{-1 / \rho_{i}}
$$

$X_{i}$ : Composite goods.

The Household demand of the functions for Income, Consumption and Savings is built on the assumed Cobb-Douglas-type preference. The Household consumes a composite good that is composed of domestic goods and imported goods. The Household will be saving a share of income after consumption.

$$
U=\prod_{i=1}^{n} C_{i}^{\alpha_{i}}
$$

$U$ : Utility of the Household, $C_{i}$ : Household consumption of the $i$ th composite good

$$
C_{i}=\frac{\alpha_{i}(Y-S)}{P_{X_{i}}}, \quad S=\delta Y
$$


$\delta$ : Saving rate.

The Government sector receives revenue in the form of direct taxes, indirect taxes and tariffs. The Government is assumed to have fixed government expenditures by sectors and save the rest of the income. This is expressed in Eqs. (8) and (10). The Foreign savings show the (negative) Balance of trade valued at the international market price and are expressed in Eq. (11).

$$
\begin{aligned}
& \mathrm{GR}=\sum_{i=1}^{n} r_{i} P_{D_{i}} \mathrm{XD}_{i}+\operatorname{tr}\left[P_{L} L^{*}+P_{K_{i}} K_{i}\right]+\sum_{i=1}^{n} \tau_{i} P_{W M_{i}} M_{i} \\
& \mathrm{G}_{\mathrm{i}}=\overline{G_{i}} \\
& \mathrm{GS}=\mathrm{GR}-\sum_{i=1}^{n} P_{X_{i}} G_{i} \\
& F=\sum_{i=1}^{n} P_{\mathrm{WM}_{i}} M_{i}-\sum_{i=1}^{n} P_{\mathrm{WE}_{i}} E_{i}
\end{aligned}
$$

$G_{i}$ : Government expenditure on the $i$ th composite good, GR: Government revenue, GS: Government savings, tr: Direct tax rate, $\tau_{i}$ : Tariff rate for the $i$ th good, $F$ : Foreign savings, $P_{\mathrm{WM}_{i}}$ : International market price for the $i$ th imported good, $P_{\mathrm{WE}_{i}}$ : International market price for the $i$ th exported good.

The market for capital, the market for composite goods and the market for input factors are assumed to be clear according to the resulting equilibrium of market demand and supply.

\subsection{Parameter estimation}

CGE models are simultaneous models that consist of a system of equations. The equations that describe the economy are able to grant the researcher ample flexibility in analyzing the economy. However, the caveat is that the model is dependent on the behavioral parameters of the expressed economy. Hence, the determining the parameters affects the model outcome. The determining the parameters, unfortunately, poses great hurdles for the researcher. This is so, because a vast amount of detailed data are required to apply widely used techniques such as least squares methods to estimate the necessary parameters. Often, such data are not available. Even when such a dataset is available, it still poses great restrictions such as inevitable averaging out of the developmental change when using longitudinal data to analyze the economy. As shown in Gallaway et al. (2003), and noted in Feenstra et al. (2018), long-run estimate results of Armington elasticities tend to be greater, at times by fivefold, than short-run estimates. Hence, for an economy that has experienced drastic change as that of Korea, it is quite unsuitable to use long time series data covering several decades to investigate the recent economy. So, this paper uses the SAM for the years 2010, 2011, 2012 and 2013 to estimate the Armington elasticities for the year 2013 to best reflect the economic characteristics of the 2013 Korean economy. 
In practical application, researchers rely on existing studies to borrow parameters or calibrate the parameters to the given data when dealing with the issue of behavioral parameters (Wing 2004). This often leaves room for criticism of the models regarding the parameters used. Critics argue that the borrowed or calibrated parameters that were used lack theoretical and empirical justification (Go et al. 2016). A feasible method which may be utilized when facing such a situation of insufficient data is the maximum entropy method. The maximum entropy method as proposed by Shannon is actually a familiar technique within the CGE model literature as it is utilized in adjusting the SAM matrix alongside the RAS method. However, it may also be utilized to estimate the behavioral parameters of the model using a small number of data points. Golan, Judge and Miller (1996) show how this method may be applied to the economic context and be used as an estimation technique. This approach allows for the data to be reflected more realistically in the estimates (Cook and Harslett 2015). The maximum entropy principle as put forth by Jaynes (1957) states that at each stage of a given situation with the then available data, the 'best that could have been done with the given information' is when the entropy is maximized.

The parameters of interest in this paper are the Armington elasticity of substitution. In the context of international trade, the elasticity of substitution of a given good differentiated by place of origin is of obvious importance. The Armington composite good is given as Eq. (5) in our set up. The Armington elasticity of substitution is then $\sigma_{i}=\frac{1}{1+\rho_{i}}$.

The first-order condition for the Armington function is:

$$
\frac{M_{i}}{\mathrm{XS}_{i}}=\left(\frac{P_{S_{i}}}{P_{M_{i}}} \frac{D_{i}}{\left(1-D_{i}\right)}\right)^{\frac{1}{1+\rho_{i}}}
$$

From this first-order condition, the problem of estimating the Armington elasticity by log linearization becomes the following:

$$
\ln \left(\frac{M_{i}}{\mathrm{XS}_{i}}\right)=\sigma_{i} \ln \left(\frac{D_{i}}{1-D_{i}}\right)+\sigma_{i} \ln \left(\frac{P_{S_{i}}}{P_{D_{i}}}\right)
$$

And thus estimating the following:

$$
\ln \left(\frac{M_{i t}}{\mathrm{XS}_{i t}}\right)=\beta_{1}+\beta_{2} \ln \left(\frac{P_{S_{i t}}}{P_{D_{i t}}}\right)+e_{i t}
$$

$\beta_{2}$ is the parameter to be estimated.

In applying the maximum entropy method, we need to consider first a parametric space support $z_{k}=\left(z_{k l}, \ldots, z_{k M}\right)^{\prime}$ where $k=1,2$ and $M=5$. That is, for the two parameters to be estimated, we will consider five possible outcomes (values). Each of the outcomes will be realized with corresponding probabilities $p_{k}=\left(p_{k 1}, \ldots, p_{k M}\right)^{\prime}$. Hence, the vector of parameters $\beta=\left(\beta_{1}, \beta_{2}\right)^{\prime}$ may be expressed as follows:

$$
\beta=Z p=\left[\begin{array}{cc}
z_{1}^{\prime} & 0 \\
0 & z_{2}^{\prime}
\end{array}\right]\left[\begin{array}{l}
p_{1} \\
p_{2}
\end{array}\right]
$$

This specification allows this method to have a Bayesian interpretation. For a range of possible outcomes, the researcher assigns 'prior' probabilities of the outcome actually 
being realized. Then, by maximizing the entropy, the researcher may obtain an updated 'posterior' probability of the outcomes. As is with all Bayesian statistics, the specifying the 'priors' is a critical issue (Henderson et al. 2015). Yet, it allows the researcher to incorporate all the 'prior' knowledge she has regarding the problem at hand. The researcher may opt to use uninformative priors, i.e., uniform probability for all possible outcomes, or use informative priors reflecting the researcher's idea of how the reality may play out. We know that $\rho_{i}>-1$ should hold. Hence, $\sigma_{i}=\frac{1}{1+\rho_{i}}>0$ should also hold. So, for this paper, we assume that the Armington elasticities should fall within the range of $[0,15]$ and assign our priors for the support values based on previous work regarding Armington elasticities. We assign the highest probability to the value reported in previous researches such as Cho and Son (2007), Son and Shin (1996) and Shin $(1996,1999,2008)$ that fall within the assumed range of support values.

Likewise for the error terms $e \in \mathbb{R}^{T}$ :

Support $v_{t}=\left(v_{1}, \ldots, v_{J}\right)^{\prime}$ where $J=3$ with corresponding weights $w_{t}=\left(w_{1 t}, \ldots, w_{J t}\right)^{\prime}$ where $t$ is the time subscript. Then, the error term may be expressed as follows:

$$
e=V w=\left[\begin{array}{ccc}
v^{\prime} & \ldots & 0 \\
\vdots & \ddots & \vdots \\
0 & \ldots & v^{\prime}
\end{array}\right]\left[\begin{array}{c}
w_{1} \\
\vdots \\
w_{T}
\end{array}\right]
$$

We assume the support vector of $v_{t}=\left[-3 \sigma_{y} 03 \sigma_{y}\right]^{\prime}$ where $\sigma_{y}$ is the sample standard deviation.

Now, we want to maximize Shannon's 'entropy' measure as given in Shannon (1948):

$$
H=-\sum_{i}^{m} p_{i} \log p_{i}
$$

where $0 \log 0=0$.

Then, the generalized maximum entropy estimation problem becomes the following according to Golan et al. (1996):

$$
\max _{p, w} H(p, w)=-p^{\prime} \ln (p)-w^{\prime} \ln (w)
$$

under the constraints:

$$
\begin{aligned}
& \ln \left(\frac{M_{i t}}{X S_{i t}}\right)=\beta_{1}+\beta_{2} \ln \left(\frac{P_{S_{i t}}}{P_{D_{i t}}}\right)+e_{i t} \\
& 1_{k}=\left(I_{k} \otimes 1_{M}^{\prime}\right) \\
& 1_{t}=\left(I_{t} \otimes 1_{J}^{\prime}\right)
\end{aligned}
$$

We use the SAM for the years 2010, 2011, 2012 and 2013 to obtain the Armington elasticities to be used in the CGE model for the year 2013.

Estimation results for the Armington elasticities for each industrial sector are given in Table 3. 
Table 3 Estimation results of the Armington elasticity

\begin{tabular}{llllllllll}
\hline $\mathbf{s 0 1}$ & $\mathbf{s 0 2}$ & $\mathbf{s 0 3}$ & $\mathbf{s 0 4}$ & $\mathbf{s 0 5}$ & $\mathbf{s 0 6}$ & $\mathbf{s 0 7}$ & $\mathbf{s 0 8}$ & $\mathbf{s 0 9}$ & $\mathbf{s 1 0}$ \\
\hline 1.491 & 1.2 & 1.121 & 0.98 & 1.211 & 1.689 & 1.406 & 1.249 & 1.278 & 1.329 \\
\hline $\mathbf{s 1 1}$ & $\mathbf{s 1 2}$ & $\mathbf{s 1 3}$ & $\mathbf{s 1 4}$ & $\mathbf{s 1 5}$ & $\mathbf{s 1 6}$ & $\mathbf{s 1 7}$ & $\mathbf{s 1 8}$ & $\mathbf{s 1 9}$ \\
\hline 1.048 & 1.374 & 1.366 & 1.2 & 1.2 & 1.2 & 1.2 & 1.2 & 1.201 \\
\hline
\end{tabular}

\section{Results and Discussion}

The scenarios to investigate for this paper reflect the impact of external shocks in the form of changes in the crude oil price. This research was inspired by the current trend in crude oil prices, which seems to display a 'new' trend in crude oil prices that deviates from the preceding behavior. As well as the decline in crude oil price, the paper also looks at the cases of the crude oil price rising. As a small open economy that is heavily dependent on exporting goods and importing commodities, the Korean economy is expected to be greatly impacted by the trends of the crude oil price.

However, the crude oil price and the Korean market import price for crude oil and hence the consumer price for petroleum products do not have a one-to-one matching relationship. This is so, for the determining of the market import price of crude oil is a very complex process and also the incorporation of fixed tax levied on petroleum product prices dilutes the effects of the changes in crude oil price. Hence, the market price of the petroleum products does not directly reflect the changes in crude oil price. Thus, this paper looks at scenarios of when the crude oil price declines and rises by 10 and $15 \%$, respectively, and how the changes affect the Korean economy. The size of the increment and decrement of the crude oil price is just 'set' at 10 and 15\%, since a change in crude oil price would not 'naturally' affect the consumer prices. Due to the process involved, determining a clear relationship between the changes in the crude oil price and its import market price and also with the consumer prices for petroleum products is not a straightforward task. Further research into the policy and pricing mechanism and the relation with the market price and the effects on the market price should be greatly helpful for research in vein with this paper.

Also as the I-O table for 2013 (which is the most recent table available) is used for this paper, the table depicts an economy that within a different economic context. That is, the table of 2013 does not reflect the global economy in which the crude oil prices have hit historical lows. Hence, the interpretation of the simulation results needs to take this aspect into consideration. However, since the economic system and the technology can be assumed to not drastically change over the course of a year, looking at the Korean economy of 2013 to gain insight into how the economy in a time of a low crude oil price (starting in the latter half of 2014) may react should be still relevant. The simulations of the economy in this paper proceed with all such aspects in consideration.

First, results of a fall in crude oil prices by 10 and 15\% are shown in Tables 4 and 5, respectively.

According to Tables 4 and 5, in case of a fall in crude oil price, the import demand of crude oil is shown to have increased. As all of the crude oil import is used as intermediate input for petroleum products, the Petroleum Products sector (S08) is shown to 
Table 4 The effects of a $10 \%$ decrease in crude oil domestic prices

\begin{tabular}{lcrccc}
\hline $\mathbf{- 1 0 \%}$ & Output (\%) & VA (\%) & Price (\%) & Export (\%) & Import (\%) \\
\hline S01 & 0.845 & 1.546 & 0.668 & -2.347 & 0.985 \\
S02 & -0.397 & 0.510 & 1.114 & -4.534 & 1.007 \\
S03 & 12.811 & 13.455 & 0.724 & N/A & 27.241 \\
S04 & -0.285 & 0.250 & 0.740 & N/A & 0.978 \\
S05 & 0.350 & 1.637 & 0.216 & -0.440 & 0.658 \\
S06 & 0.360 & 1.287 & 0.885 & -2.406 & 1.301 \\
S07 & 0.617 & 1.644 & 0.233 & -0.281 & 0.731 \\
S08 & 19.108 & 29.127 & -10.972 & 54.475 & -8.732 \\
S09 & 0.234 & 1.982 & -0.177 & 0.743 & -0.253 \\
S10 & -10.815 & -10.393 & 2.482 & -14.314 & -1.915 \\
S11 & -2.250 & -1.572 & 1.615 & -5.806 & 1.886 \\
S12 & -2.304 & -1.606 & 2.001 & -5.876 & 2.957 \\
S13 & -1.850 & -0.933 & 0.899 & -4.890 & -0.956 \\
S14 & 1.084 & 2.645 & -0.070 & 1.360 & 1.005 \\
S15 & 0.947 & 2.181 & 0.150 & 0.358 & 1.023 \\
S16 & 2.073 & 3.165 & 0.493 & 0.139 & 2.329 \\
S17 & 7.673 & 8.884 & 0.785 & 4.443 & 8.099 \\
S18 & 2.475 & 5.520 & -1.716 & 7.524 & -0.361 \\
S19 & 1.852 & 2.378 & 1.199 & -2.562 & 2.685 \\
\hline
\end{tabular}

Table 5 The effects of a $15 \%$ decrease in crude oil domestic prices

\begin{tabular}{lcrrrr}
\hline $\mathbf{- 1 5 \%}$ & Output (\%) & VA (\%) & Price (\%) & Export (\%) & Import (\%) \\
\hline S01 & 1.277 & 2.430 & 1.094 & -3.912 & 1.504 \\
S02 & -0.467 & 0.929 & 1.701 & -6.692 & 1.674 \\
S03 & 25.471 & 26.666 & 1.188 & N/A & 51.080 \\
S04 & -0.441 & 0.452 & 1.219 & N/A & 1.641 \\
S05 & 0.397 & 2.475 & 0.346 & -0.868 & 0.891 \\
S06 & 0.544 & 2.013 & 1.395 & -3.790 & 2.022 \\
S07 & 0.894 & 2.613 & 0.386 & -0.594 & 1.084 \\
S08 & 36.607 & 54.740 & -17.221 & 103.171 & -13.663 \\
S09 & 0.253 & 3.053 & -0.304 & 1.127 & -0.582 \\
S10 & -15.984 & -15.304 & 3.829 & -21.054 & -2.888 \\
S11 & -3.706 & -2.629 & 2.502 & -9.092 & 2.612 \\
S12 & -3.818 & -2.705 & 3.066 & -9.182 & 4.127 \\
S13 & -2.872 & -1.442 & 1.398 & -7.501 & -1.501 \\
S14 & 1.989 & 4.530 & -0.107 & 2.415 & 1.867 \\
S15 & 1.653 & 3.685 & 0.248 & 0.678 & 1.780 \\
S16 & 3.576 & 5.352 & 0.779 & 0.496 & 3.986 \\
S17 & 10.460 & 12.389 & 1.203 & 5.435 & 11.129 \\
S18 & 4.319 & 9.301 & -2.795 & 12.813 & -0.418 \\
S19 & 2.799 & 3.643 & 1.888 & -4.109 & 4.117 \\
\hline & & & & & \\
\hline
\end{tabular}

be greatly affected by a fall in crude oil prices. As for the manufacturing industries, the Heavy Chemical Industry (S09) shows a large share of Petroleum Products in its input and thus is shown to be more affected by the change in crude oil price than other manufacturing sectors. However, as a large share of input for Heavy Chemical Industry is from 
itself, the effect itself is not very large. In the case of other manufacturing industries, Electrical and Electronics (S10), Precision Machinery (S11), Transportation Equipment (S12) and Other Manufacturing (S13) sectors are shown to be affected by the Heavy Chemical Industry. However, as the Heavy Chemical Industry reacts in a quite muted manner to a change in crude oil prices, the output of aforementioned industries (other than the Heavy Chemical Industry) reacts unlike the Heavy Chemical Industry does to the change in crude oil price. The output of the industries is shown to actually decrease with a fall in crude oil prices.

As for Construction (S17), Petroleum Products comprises a large share of inputs into the sector, and Heavy Chemical Industry also comprises a large share of inputs into Construction, leading the sector to react in the same manner as the Heavy Chemical Industry. Also, for Transportation Services (S18), as Petroleum Products comprises a large share of inputs into the sector, the sector is shown to be largely affected by changes in crude oil prices.

Looking at the results from the perspective of technology intensity, industries with low technology intensity are shown to be affected in a positive direction. This may be interpreted as the industries having a more 'straightforward' effects from a fall in crude oil price. In contrast, for more technology intensive industries, the effect of change crude oil price is channeled through more complicated layers of production showing results that may seem counterintuitive. Also, Service and Miscellaneous (S19) sector is shown to increase its output with a fall in crude oil price.

Tables 6 and 7 below show the effects to the Korean economy brought on by a rise in crude oil prices by 10 and $15 \%$ respectively. As with the case of the crude oil price falling, we look at how the GDP is affected by a change in crude oil price.

Table 6 The effects of a $10 \%$ increase in crude oil domestic prices

\begin{tabular}{lccccc}
\hline $\mathbf{+ 1 0 \%}$ & Output (\%) & VA (\%) & Price (\%) & Export (\%) & Import (\%) \\
\hline S01 & -0.862 & -1.387 & -0.502 & 1.577 & -0.966 \\
S02 & 0.521 & -0.345 & -1.077 & 4.772 & -0.848 \\
S03 & -5.724 & -6.103 & -0.540 & UNDF & -15.432 \\
S04 & 0.159 & -0.216 & -0.542 & UNDF & -0.767 \\
S05 & -0.607 & -1.644 & -0.166 & 0.003 & -0.842 \\
S06 & -0.378 & -1.176 & -0.766 & 2.070 & -1.201 \\
S07 & -0.679 & -1.389 & -0.165 & -0.045 & -0.759 \\
S08 & -10.000 & -16.388 & 9.789 & -29.470 & 7.654 \\
S09 & -0.405 & -1.854 & 0.124 & -0.756 & -0.066 \\
S10 & 12.550 & 12.224 & -2.362 & 16.780 & 2.363 \\
S11 & 1.728 & 1.161 & -1.502 & 5.261 & -2.263 \\
S12 & 1.626 & 1.049 & -1.928 & 5.263 & -3.620 \\
S13 & 1.884 & 1.042 & -0.819 & 4.861 & 1.029 \\
S14 & -0.638 & -1.881 & 0.074 & -0.922 & -0.556 \\
S15 & -0.624 & -1.552 & -0.110 & -0.196 & -0.679 \\
S16 & -1.534 & -2.408 & -0.421 & 0.097 & -1.745 \\
S17 & -9.844 & -10.782 & -0.748 & -7.168 & -10.186 \\
S18 & -1.671 & -4.094 & 1.369 & -5.376 & 0.456 \\
S19 & -1.879 & -2.313 & -1.051 & 2.043 & -2.593 \\
\hline
\end{tabular}


Table 7 The effects of a $15 \%$ increase in crude oil domestic prices

\begin{tabular}{lccccc}
\hline $\mathbf{+ 5 \%}$ & Output (\%) & VA (\%) & Price (\%) & Export (\%) & Import (\%) \\
\hline S01 & -1.315 & -2.051 & -0.701 & 2.095 & -1.460 \\
S02 & 0.793 & -0.507 & -1.614 & 7.265 & -1.264 \\
S03 & -7.337 & -7.849 & -0.753 & UNDF & -20.984 \\
S04 & 0.169 & -0.343 & -0.751 & UNDF & -1.112 \\
S05 & -1.015 & -2.501 & -0.231 & -0.172 & -1.339 \\
S06 & -0.584 & -1.750 & -1.116 & 2.996 & -1.784 \\
S07 & -1.052 & -2.021 & -0.225 & -0.188 & -1.160 \\
S08 & -13.358 & -22.241 & 14.408 & -39.569 & 11.163 \\
S09 & -0.670 & -2.765 & 0.176 & -1.168 & -0.190 \\
S10 & 19.852 & 19.400 & -3.528 & 26.584 & 3.851 \\
S11 & 2.438 & 1.619 & -2.230 & 7.751 & -3.523 \\
S12 & 2.172 & 1.342 & -2.887 & 7.664 & -5.712 \\
S13 & 2.899 & 1.647 & -1.209 & 7.373 & 1.620 \\
S14 & -0.866 & -2.646 & 0.115 & -1.310 & -0.738 \\
S15 & -0.859 & -2.163 & -0.153 & -0.266 & -0.935 \\
S16 & -2.210 & -3.466 & -0.611 & 0.148 & -2.514 \\
S17 & -15.608 & -16.914 & -1.117 & -11.832 & -16.120 \\
S18 & -2.335 & -5.825 & 1.968 & -7.585 & 0.690 \\
S19 & -2.857 & -3.485 & -1.539 & 2.890 & -3.896 \\
\hline
\end{tabular}

The crude oil prices rising are shown to have opposite effects as the case of the crude oil prices falling. However, the size of the effects can be seen to be smaller in the case of the crude oil price rising. This implies that the system of the Korean economy is such that it is affected more by a fall in the crude oil prices than a rise. The results of the simulation of this paper may be overstated/understated stemming from the fact that the model is not multi-regional but a national model (for a small open economy) and that it is a static model. Also, as the closure condition for solving the CGE model, nominal exchange rates and the price of domestic goods were fixed and the balance of trade was unfixed to be variable. These constraints of the model affect the simulation results. As with all empirical work, the simulation results of this paper should be interpreted with the context in mind.

\section{Conclusions}

The analysis of this paper shows that the characteristics of the economic system depicted by the constructed SAM affect the simulation results. As is aforementioned, a fall in crude oil price impacts the economy, so import demand increases. This in turn affects the Petroleum Products, and this sector in turn affects the industry sector that is linked with the Petroleum Products sector. The size of the effects of change in crude oil price is can be seen to be dependent on the makeup of the inputs for that sector. If the inputs are largely composed of Petroleum Products, the effects of changes in crude oil price are large. However, if the share of inputs to itself is relatively large, then the effects of the change in crude oil price may be muted or even shown to have an adverse effect on outputs. 
Looking at international trade, the fall in crude oil price does not translate into an increase in the output for industry sectors that are responsible for the bulk of export volume. This is a result of the constraint of the model aforementioned and the industrial structure complicating the channel of the impact of the crude oil price change. Hence, effects of the fall of crude oil price are not always shown to be evenly advantageous to all industry sectors.

These conclusions lead to the fact that the model still has room for improvement. First, one of the major critiques the CGE model faces is the lack of justification of the behavioral parameters used in the model. Using a more justified set of behavioral parameter (be it theoretical or empirical) will enhance the robustness of the simulation results. Also constructing a multi-regional model building upon international input-output tables (IIOT) may improve the analytic capacity of the CGE model. Such are the directions of the future extensions of the current research.

\title{
Authors' contributions
}

Authors YKK and HL have equally contributed to designing of the research, the process of data collection and calculation as well as drafting and revision of the manuscript. Both authors read and approved the final manuscript.

\section{Acknowledgements}

None.

\section{Competing interests}

The authors declare that they have no competing interests.

\section{Availability of data and materials}

The dataset supporting the conclusions of this article is available in Economic Statistics System of Bank of Korea (http:// ecos.bok.or.kr/).

Ethics approval and consent to participate

Not applicable.

\section{Publisher's Note}

Springer Nature remains neutral with regard to jurisdictional claims in published maps and institutional affiliations.

Received: 19 February 2018 Accepted: 15 June 2018

Published online: 13 July 2018

\author{
References \\ Armington P (1969) A theory of demand for products distinguished by place of production. IMF Staff Pap 16:159-178 \\ Cho KY, Son YH (2007) Research on the economic effects of an oil supply crisis. Resour Environ Econ Res 16(1):27-63 \\ Cook L, Harslett P (2015) An introduction to entropy estimation of parameters in economic models. Presented at the \\ 18th annual conference on global economic analysis, Melbourne, Australia. Purdue University, West Lafayette, IN. \\ Global Trade Analysis Project (GTAP) \\ Feenstra RC, Luck P, Obstfeld M, Russ KN (2018) In search of the Armington elasticity. Rev Econ Stat 100:135-150 \\ Gallaway MP, McDaniel CA, Rivera SA (2003) Short and long-run industry-level estimates of U.S. Armington elasticities. N \\ Am J Econ Finance 14:49-68 \\ Go DS, Lofgren H, Ramos FM, Robinson S (2016) Estimating parameters and structural change in CGE models using a \\ Bayesian cross-entropy estimation approach. Econ Model 52:790-811 \\ Golan A, Judge G, Miller D (1996) Maximum entropy econometrics: robust estimation with limited data. Wiley, New York \\ Henderson H, Golan Amos, Seabold Skipper (2015) Incorporating prior information when true priors are unknown: an \\ information-theoretic approach for increasing efficiency in estimation. Econ Lett 127:1-5 \\ International Monetary Fund (2016) The world economic outlook (WEO) October 2016. http://www.imf.org/external/ \\ pubs/ft/weo/2016/01/weodata/index.aspx. Retrieved 10 Mar 2017 \\ Jaynes ET (1957) Information theory and statistical mechanics. Phys Rev 106(4):620-630 \\ LeontiefW (1936) Quantitative input and output relations in the economic system of the United Stated. Rev Econ Stat \\ 18:105-125 \\ Shannon CE (1948) A mathematical theory of communication. Bell Syst Tech J 27:379-423, 623-656 \\ Shin DC (1996) Research on the elasticity of substitution between imported goods and domestic goods. Econ Res \\ 44(1):101-118 \\ Shin DC (1999) The computable general equilibrium of international trade. Sae Kyung Sa, Seoul \\ Shin DC (2008) The economic effects of price change in natural gas. Resour and Environ Econ Res 17(2):59-83
}


Son YH, Shin DC (1996) The development of a computable general equilibrium model and its applications: analysis of the economic effects of electricity price. Policy Res 96-01, Korea Energy Economics Institute, pp. 1-31

Wing IS (2004) Computable general equilibrium models and their use in economy-wide policy analysis. In: The MIT joint program on the science and policy of global change, technical note, no. 6

Submit your manuscript to a SpringerOpen ${ }^{\circ}$ journal and benefit from:

- Convenient online submission

- Rigorous peer review

- Open access: articles freely available online

- High visibility within the field

- Retaining the copyright to your article

Submit your next manuscript at $\boldsymbol{\Delta}$ springeropen.com 